A N N A L E S Annales de Bretagne et des Pays de l'Ouest

\title{
Les marchands français de Cadix et la crise de la Carrera de Indias (1778-1828)
}

Pierrick Pourchasse

\section{(2) OpenEdition}

Édition électronique

URL : https://journals.openedition.org/abpo/4927

DOI : $10.4000 / a b p o .4927$

ISBN : 978-2-7535-8021-3

ISSN : 2108-6443

Éditeur

Presses universitaires de Rennes

Édition imprimée

Date de publication : 20 décembre 2019

Pagination : 238-239

ISBN : 978-2-7535-8019-0

ISSN : 0399-0826

\section{Référence électronique}

Pierrick Pourchasse, "Les marchands français de Cadix et la crise de la Carrera de Indias (1778-1828)», Annales de Bretagne et des Pays de l'Ouest [En ligne], 126-4 | 2019, mis en ligne le 22 janvier 2020, consulté le 05 janvier 2023. URL : http://journals.openedition.org/abpo/4927 ; DOI : https://doi.org/ 10.4000/abpo.4927 
Le livre d'Arnaud Bartolomei est issu d'une thèse soutenue en 2007 à l'université de Provence portant sur les marchands français de Cadix au cours d'une période tourmentée du commerce hispano-américain entre l'instauration du commerce libre (comercio libre) en 1778 et la disparition de toute règlementation en 1828 après l'indépendance des colonies espagnoles d'Amérique. L'objectif est d'étudier la résistance de la colonie française installée dans le port espagnol qui survit malgré les vicissitudes du temps. Pour y répondre trois questions guident cette recherche : pourquoi les marchands choisissent-ils de s'installer à Cadix? Pourquoi y restent-ils en ces temps très difficiles? Pourquoi demeurent-ils Français alors qu'il est facile d'obtenir la naturalité espagnole?

Cadix a le monopole exclusif du commerce colonial espagnol depuis le $\mathrm{xVI}^{\mathrm{e}}$ siècle, privilège définitivement reconnu en 1680. Après la paralysie des échanges hispano-américains pendant la guerre de Succession d'Espagne, ses avantages sont renforcés avec le transfert de la Casa de la Contratación en 1717. Cependant entre 1765 et 1789, la règlementation est progressivement démantelée, notamment avec la promulgation des décrets du comercio libre en octobre 1778. Cadix cesse d'être privilégiée dans le but de faire participer d'autres ports espagnols au commerce atlantique et de dégager le commerce colonial de l'emprise du négoce étranger. Parallèlement, un tarif douanier plus protectionniste est appliqué ce qui, par exemple, fait perdre aux toiles bretonnes les privilèges douaniers dont elles bénéficiaient aux dépens de leurs rivales silésiennes depuis 1698 (Convenio d'Eminente).

La période étudiée est troublée par de nombreux événements : guerre d'Amérique, krach de 1783, guerres révolutionnaires et napoléoniennes (conflit franco-espagnol de 1793 à 1808), montée en puissance du commerce britannique... Arnaud Bartolomei constate que, malgré la perte de ses privilèges et une grande irrégularité des échanges due au contexte politique international, le commerce gaditan reste prospère en raison de son intégration dans les circuits atlantiques et de la vitalité de ses colonies marchandes étrangères. Si le monopole est aboli, les relations avec l'Amérique restent assurées de façon exclusive par Cadix dans les années 1780 et 1790. Ensuite, le blocus britannique de 1797 à 1808, hormis les trois années après la paix d'Amiens, provoque la quasi rupture des relations avec l'Amérique. Cependant, pour l'auteur, la vraie crise qui aboutit à l'effondrement final date de 1823, après le départ de la plupart des négociants étrangers avec leurs capitaux et l'établissement de relations directes entre l'Europe et les nouvelles républiques américaines. Au xIX ${ }^{\mathrm{e}}$ siècle, le commerce de Cadix retrouve une nouvelle dynamique fondée sur les exportations de la terre andalouse.

En cette fin de XvIII siècle, si les exportations françaises reculent, les négociants français, au nombre d'environ cinq cents, maintiennent leur position en diversifiant leurs activités, prenant part par exemple au commerce des toiles de Silésie ou des produits manufacturés anglais. La période du comercio libre est marquée par une rentabilité soutenue mais très dépendante de la Carrera de Indias. Cependant, 
les années 1790, notamment après l'exécution de Louis XVI, sont marquées par un "vertigineux déclin " de la colonie qui est pratiquement réduite à néant, même si elle tente de se reformer lors des périodes plus calmes. De nombreux négociants ont une fin tragique à l'exemple de Bernard Magon de Campaneu, l'héritier d'une des plus prestigieuses familles de Saint-Malo. Finalement, la colonie s'efface dans les années 1820 et il ne reste plus qu'un consulat pour gérer le passage des Français.

Arnaud Bartolomei remarque qu'au cours de cette période très agitée, la colonie française qui reste à Cadix essaie de survivre malgré la rupture des relations hispano-américaines alors qu'elle fondait sa prospérité sur le commerce colonial espagnol. De nouvelles stratégies se mettent en place dans ce port carrefour entre Atlantique et Méditerranée où les opportunités commerciales et financières sont nombreuses. Pour certains, ce peut être l'activité corsaire, et Cadix devient un des centres de la course française au temps du blocus britannique. Le bilan reste cependant très mitigé et peu de familles parviennent à surmonter le naufrage de la Carrera de Indias.

Ainsi, une partie des négociants reste dans une place où ils sont à la merci d'un déclassement pour des raisons autres que l'enrichissement. Ceux-ci choisissent de se maintenir à Cadix car ils y ont fondé des familles, sont intégrés dans la société locale et finalement gardent peu de liens, hormis commerciaux, avec la France, leur pays d'origine. La dernière partie de l'ouvrage analyse l'intégration de ces étrangers selon leur temps de résidence, leur vie privée ou encore leur statut social ce qui explique le retour en France ou le désir de rester en Espagne. La minorité qui choisit de demeurer à Cadix manifeste cependant un profond attachement à l'identité française qui leur garantit certains privilèges dans la conduite de leurs affaires.

Arnaud Bartolomei présente une étude solide, parfaitement documentée et reposant sur une excellente connaissance des sources françaises et espagnoles. Si elle explique la grande capacité d'adaptation des négociants de Cadix aux temps difficiles de la fin du XVIII ${ }^{\mathrm{e}}$ siècle et du début du XIX ${ }^{\mathrm{e}}$ siècle, elle montre aussi le peu d'anticipation aux grands changements politiques et économiques à venir.

Pierrick POURCHASSE

TANGUY-SchroËR, Judith (dir.), Les grandes Fermes du Trégor. Le temps de la reconstruction 1770-1840, Douarnenez, Locus Solus, 2019, 128 p.

Depuis les années 1960, l'habitat rural a souvent été au centre des préoccupations et publications de l'Inventaire du patrimoine de Bretagne. Les premiers volumes consacrés à l'habitat vernaculaire de deux régions du centre Bretagne (cantons de Carhaix et du Faouët) sont devenus au fil des ans des classiques. Alors que la "révolution agricole bretonne " battait son plein, ces deux ouvrages avaient eu pour mission de faire savoir aux Bretons que ce patrimoine bâti n'avait rien de méprisable et qu'il participait d'une culture paysanne en voie de disparition. En consacrant un petit ouvrage, très bien documenté et illustré aux grandes fermes du Trégor, l'équipe menée 